\title{
DISTRIBUTION OF PEDIATRIC CATARACTS BY SEX, AGE GROUPS, LATERALITY, TYPE AND PRESENTATION IN POPULATION OF D.I.KHAN DISTRICT, PAKISTAN
}

\author{
Muhammad Kamran Khalid ${ }^{1}$, Iftikhar Ahmad², Muhammad Ayub Khan', Muhammad Sharjeel', \\ Muhammad Irfan ${ }^{3}$, Muhammad Marwat ${ }^{1}$ \\ Departments of ${ }^{1}$ Ophthalmology \& ${ }^{2}$ Community Medicine, Gomal Medical College, D.I.Khan, ${ }^{3}$ Department of \\ Ophthalmology, Hayatabad Medical Complex, Peshawar, Pakistan
}

\begin{abstract}
Background: Pediatric cataracts cause significant visual disability worldwide. The objectives of this study were to determine the distribution of pediatric cataracts by sex, age groups, laterality, type and presentation in population of D.I.Khan District, Pakistan.

Materials \& Methods: This descriptive study was carried out at Department of Ophthalmology, Gomal Medical College, D.I.Khan, Pakistan from January 2015 to December 2015. Sample was collected from Eye unit, DHQ Teaching Hospital, D.I.Khan. Pediatric cataract patients under 14 years of age were included in the study. Demographic variables were sex and age groups. Research variables were laterality, type and presentation. All variables being nominal were analyzed through frequency and percentages. The observed and expected distribution of pediatric cataract by sex, age groups, laterality, type and presentation were respectively tested by chi-square goodness of fit test.

Results: Out of a sample of 47 patients, $29(61.7 \%)$ were boys and $18(38.3 \%)$ girls, $22(46.81 \%)$ were $<5$ years and 25 (53.19\%) $5-14$ years of age. Thirty three (70.21\%) had unilateral and $14(29.79 \%)$ bilateral cataracts. Type was congenital/ developmental in 27 (57.45\%) patients and traumatic in 20 (42.55\%). Presentation was by defective vision in 23 (48.94\%), leukocoria 14 (29.79\%), strabismus 7 (14.89\%) and screening in $3(6.38 \%)$ cases. The observed distribution of pediatric cataract by sex $(p=.0158)$, age groups $(p=.00002)$, laterally $(p=<.00001)$ and type $(p=.00001)$ was similar to expected, while for presentation, it was different than expected $(p=.1033)$.

Conclusion: The prevalence of pediatric cataract was higher for boys than girls and higher for older children (5-14 years) than younger ( $<5$ years) children. Unilateral were more common than bilateral cataracts and the congenital/ developmental were more common than traumatic cataracts. Defective vision was the most common presentation of pediatric cataracts.
\end{abstract}

KEY WORDS: Pediatric Cataract; Congenital; Blindness; Prevelenc; Boys; Girls; Strabismus; Pakistan.

This article may be cited as: Khalid MK, Ahmad I, Khan MA, Sharjeel M, Irfan M. Marwat M. Distribution of pediatric cataracts by sex, age groups, laterality, type and presentation in population of D.I.Khan District, Pakistan. Gomal J Med Sci 2019 Oct-Dec; 17 (3):123-30. https://doi.org/10.46903/gjms/17.04.2025

\section{INTRODUCTION}

1.1 Background: Globally cataract is the leading cause of treatable blindness. It is also true in cases of pediatric cataracts. According to a global review

\section{Corresponding Author:}

Dr. Muhammad Kamran Khalid

Associate Professor, Department of Ophthalmology

Gomal Medical College, D.I.Khan, Pakistan

E-mail: drkamrankhalid786@gmail.com

Date Submitted: 13-02-2019

Date Revised: 22-05-2019

Date Accepted: 10-06-2019 by Shamanna \& Muralikrishnan ${ }^{1}$ in 2004, 70 million blind-person-years are caused by childhood blindness, of which about 10 million blind-person-years (14\%) are due to childhood cataract. Another study by Rahi \& Dezateux ${ }^{2}$ on congenital cataract in the UK, from Oct. 1995 to Sep. 1996 suggested that the adjusted annual age-specific incidence of new diagnosis of congenital and infantile cataract was highest in the first year of life, being 2.49 per 10,000 Children (95\% confidence interval [Cl], 2.10-2.87). The incidence of bilateral congenital cataract is around 1.8 to 3.6/ 10,000 per year and prevalence from 0.63 to $9.74 / 10,000$ as stated by Sheeladevi ${ }^{3}$ in 2016 . In a survey done by Jadoon, et al. ${ }^{4}$ in 2007 in Pakistan, 
the crude prevalence of blindness in adults due to bilateral cataract was $1.75 \%$.

$\mathrm{Naz}$, et al. ${ }^{5}$ conducted a prevalence study at Layton Rahmatullah Benevolent Trust Free Eye Hospital (LRBT), Lahore, Pakistan from October 2013 to April 2014 and examined 38,000 children under 15 years, and found cataract in 120 (0.3\%) cases.

Equal prevalence for boys and girls was reported by Rahi \& Dezateux ${ }^{2}$; boys $52.42 \%$ (130/248) and girls $47.58 \%(118 / 248)$ in UK in 1995-96 and by Haargaard, et $\mathrm{al}^{6}$ in nation-wide Danish study in 2004 for boys $51.50 \%$ (529/1027) and girls $48.50 \%$ (498/1027).

Higher prevalence rate for boys $77.5 \%(93 / 120)$ than girls $22.5 \%(27 / 120)$ was reported by Naz, et al. ${ }^{5}$ and $60.38 \%(314 / 520)$ boys and $39.62 \%(206 / 520)$ girls by Zhu, et al. ${ }^{7}$ in a retrospective chart review for the period from April 2009 to April 2014 from Eye and ENT Hospital of Fudan University, Shanghai, China.

Higher prevalence rate for girls $53 \%(31 / 59)$ than boys $47 \%(28 / 59)$ was reported by Fakhoury, et al. ${ }^{8}$ in epidemiological study over 10 years, published in 2015 from France.

Shah, et al. ${ }^{9}$ showed $21.38 \%$ (279/1305) eyes with congenital cataract in age group 0-5 years and $78.62 \%(1026 / 1305)$ in age group 6-18 years in a study for a period from January 1999 to April 2012 in Dahod, Gujarat, India.

Rahi \& Dezateux ${ }^{2}$ noted higher prevalence rates $70.16 \%(174 / 248)$ for age group $>1$ year than $29.84 \%(74 / 248)$ for age group $\leq 1$ year in UK in 1995-96.

The following authors have reported higher prevalence for bilateral than unilateral pediatric cataracts. Naz, et al. ${ }^{5}$ showed bilateral cataracts in $75.83 \%$ $(91 / 120)$ and unilateral in $24.17 \%(29 / 120)$ cases. Zhu, et al. ${ }^{7}$ showed bilateral in $56.35 \%$ (293/520) and unilateral in $43.65 \%(227 / 520)$ cases. Fakhoury, et al. ${ }^{8}$ showed bilateral cataracts in $71 \%(42 / 59)$ and unilateral in 29\% (17/59) cases and Qi, et al. ${ }^{10}$ for the period from January 2004 to January 2012 from Shenyang, Liaoning Province, China, showed 78\% (25/32) bilateral cases and 22\% (7/32) unilateral cases.

The following authors have reported higher prevalence for unilateral than bilateral pediatric cataracts. Tartarella, et al. ${ }^{11}$ have reported unilateral in $52.66 \%$ (109/207) and bilateral in 47.34\% (98/207) cases for the period from February 2001 to January 2011 from São Paulo, Brazil. Tomkins, et al. ${ }^{12}$ found unilateral cataract in $75.34 \%(55 / 73)$ and bilateral in $24.66 \%$ $(18 / 73)$ cases in Hawassa city in rural southern Ethiopia for the period from July 31, 2007, through August 1,2008 . Shrestha \& Shrestha ${ }^{13}$ reported unilateral cataract in $67.4 \%(89 / 132)$ and bilateral in $32.6 \%$ (43/132) cases in Kathmandu, Nepal for the period from November, 2007 to June, 2009.

Almost equal prevalence is reported for unilateral
$48.8 \%(160 / 328)$ and bilateral cataracts $51.2 \%$ (168/328) from Guatemala City, Republic of Guatemala for the period from 2000 to 2007 by Zimmermann-Paiz \& Quiroga-Reyes. ${ }^{14}$

In a study for the period from 1985-1990, by Hochstrasser, et al. ${ }^{15}$ from Zürich, Switzerland, congenital/ developmental cataracts were found in $60 \%(45 / 75)$ cases while traumatic cataracts were found in $40 \%$ $(30 / 75)$ cases. Johar, et al. ${ }^{16}$ found $88.4 \%(152 / 172)$ non-traumatic cataracts and $11.6 \%(20 / 172)$ traumatic cataracts in a hospital-based etiological study of pediatric cataracts in Western India. Mohan \& Kaur ${ }^{17}$ found $72.12 \%(119 / 165)$ non-traumatic cataracts and $27.88 \%(46 / 165)$ traumatic cataracts from April 2011 to March 2014 in a hospital-based study of pediatric cataracts from Abu Road city, Sirohi district of Rajasthan state in western India.

Zhu, et al. ${ }^{7}$ form China found the mode of presentation as defective vision in $41.3 \%(214 / 520)$, leukocoria in $38.8 \%$ (202/520), strabismus in $18.3 \%$ (95/520) and through screening in $1.73 \%(9 / 520)$ cases. Fakhoury, et al. ${ }^{8}$ from France found the presentation as systematic screening in $41 \%(24 / 59)$, leukocoria in $24 \%$ (14/59) and strabismus in 19\% (11/59) cases.

1.2 Research Problems (RPs), Knowledge Gaps (KGs) \& Research Questions (RQs): Unawareness of the distribution of pediatric cataracts by sex, age groups, laterality, type and presentation in population of D.I.Khan District, Pakistan were our five research problems. Various databases/ search engines like PubMed, PubMed Central, Cochrane Database, ProQuest, ScienceDirect, Pakistan Research Repository, Google Scholar and Google were searched out. Absence of studies on these problems for our population were our five knowledge gaps. How would be the distribution of pediatric cataracts by sex, age groups, laterality, type and presentation respectively in population of D.I.Khan District, Pakistan, would be our five research questions. Answering these RQs, filling these KGs \& solving these RPs would be the rationale/ justification of our project.

\subsection{Research Objectives (RO):}

RO 1-5: To determine the distribution of pediatric cataracts by sex, age groups, laterality, type and presentation in population of D.I.Khan District, Pakistan.

RO 6-10: To compare the expected versus observed distribution of pediatric cataracts by sex, age groups, laterality, type and presentation in population of D.I.Khan District, Pakistan.

1.4 Research (Null) Hypotheses: Hypotheses are tentative answers to RQs. Having survey of the global and national literature, we came forwards with the following hypotheses.

$\mathrm{H}_{0}$ 1: The observed distribution of pediatric cataracts by sex in population of D.I.Khan District, Pakistan is same as expected. (RO 6)

$\mathbf{H}_{0}$ 2: The observed distribution of pediatric cataracts 
by age groups in population of D.I.Khan District, Pakistan is same as expected. (RO 7)

$\mathbf{H}_{0} 3$ : The observed distribution of pediatric cataracts by laterality in population of D.I.Khan District, Pakistan is same as expected. (RO 8)

$\mathbf{H}_{0} 4$ : The observed distribution of pediatric cataracts by type in population of D.I.Khan District, Pakistan is same as expected. (RO 9)

$\mathbf{H}_{\mathbf{0}} \mathbf{5}$ : The observed distribution of pediatric cataracts by presentation in population of D.I.Khan District, Pakistan is same as expected. (RO 10)

\section{MATERIALS \& METHODS}

2.1 Design, Duration \& Settings: This cross-sectional study was conducted at the Department of Ophthalmology, Gomal Medical College, D.I.Khan, Pakistan from January 2015 to December 2015. The sample was collected from Eye Unit, DHQ Teaching Hospital, D.I.Khan, Pakistan.

2.2 Population \& Sampling (size, technique, selection): D.I.Khan District is the catchment area of our hospital, having an estimated population of around 1.5 million in 2015. Assuming 30\% population of children, our reference population will be approximately 450,000 . Out of this population, a sample size of 47 was calculated through Raosoft ${ }_{\circledast}{ }^{18}$ an online sample size calculator, with margin of error of $0.91 \%$, confidence level of $95 \%$ and estimated prevalence of pediatric cataracts of $0.1 \%$ in D.I.Khan District, Pakistan. The sampling technique was consecutive, non-probability technique. All the patients with pediatric cataracts were eligible for inclusion. All cases with severe ocular pathology precluding surgical intervention were excluded.

2.3 Data Collection Plan: Demographic variables were sex (boys, girls) and age groups $(<5$ years \& 5-14 years). Research variables were laterality of cataract (unilateral, bilateral), type of cataract (congenital/ developmental, traumatic) and presentation (defective vision, leukocoria, strabismus, screening). All variables were measured on nominal scale.

\subsection{Data Analysis Plan}

2.4.1 Descriptive Statistics and Estimation of Parameter: All variables were described by count and percentage for the sample. Then interval estimate for population was calculated as $\mathrm{Cl}$ (confidence interval) for proportion at $80 \% \mathrm{CL}$ (confidence level) using the normal distribution approximation for the binomial distribution through an online statistical calculator. ${ }^{19}$

2.4.2 Hypotheses Testing: All the hypotheses were substantiated through chi-square goodness-of-fit test ${ }^{20-21}$ at alpha .05 using an online statistical calculator. ${ }^{22}$ Observed and expected counts, their difference, chi-square statistic, degree of freedom and level of significance were given.

\section{RESULTS}

3.1 Descriptive Statistics and Estimation of Parameter:

3.1.1 Out of a sample of 47 patients with pediatric cataract, the prevalence was higher for boys than girls and higher for older children (5-14 years) than younger ( $<5$ years) children. Unilateral were more than bilateral cataracts. (Table 3.1.1)

3.1.2 The prevalence of congenital/ developmental cataract was higher than traumatic cataract.

Defective vision was the most common presentation with screening the least common. (Table 3.1.2)

\subsection{Hypotheses Testing:}

3.2.1 $\mathrm{H}_{0}$ 1: The data from the study by $\mathrm{Naz}$, et al. is assumed to represent a larger population of pediatric cataracts from the province of Punjab, Pakistan. As per our null hypothesis, we expected the same distribution for our smaller population of D.I.Khan District.

Our observed distribution for boys versus girls was 29:18 $(n=47)$ against an expected distribution by $\mathrm{Naz}$, et al. of 93:27 $(n=120)$. Chi-square goodnessof-fit test was used to testify the difference between the two distributions. For comparison we need same denominator, so we adjusted the expected counts for a sample of 47 . It came to be $36: 11$ for boys versus girls as under.

Table 3.1.1: Distribution of pediatric cataracts by sex, age groups and laterality in population of D.I.Khan District, Pakistan $(n=47)$

\begin{tabular}{|l|l|c|c|c|c|}
\hline \multirow{2}{*}{ Variables } & \multirow{2}{*}{ Attributes } & \multicolumn{2}{|c|}{ Sample statistics } & \multicolumn{2}{c|}{$80 \%$ Cl for proportion } \\
\cline { 3 - 6 } & & Count & Percentage & Lower & Upper \\
\hline \multirow{3}{*}{ Sex } & Boys & 29 & 61.70 & 52.62 & 70.79 \\
\cline { 2 - 6 } & Girls & 18 & 38.30 & 29.21 & 47.38 \\
\hline \multirow{3}{*}{ Age groups } & $<5$ years & 22 & 46.81 & 37.48 & 56.14 \\
\cline { 2 - 6 } & $5-14$ years & 25 & 53.19 & 43.86 & 62.52 \\
\hline \multirow{3}{*}{ Laterality } & Unilateral & 33 & 70.21 & 61.66 & 78.76 \\
\cline { 2 - 6 } & Bilateral & 14 & 29.79 & 21.24 & 38.34 \\
\hline
\end{tabular}


Table 3.1.2: Distribution of pediatric cataracts by type and presentation in population of D.I.Khan District, Pakistan $(n=47)$

\begin{tabular}{|l|l|c|c|c|c|}
\hline \multirow{2}{*}{ Variables } & \multirow{2}{*}{ Attributes } & \multicolumn{2}{|c|}{ Sample statistics } & \multicolumn{2}{|c|}{$80 \%$ Cl for proportion } \\
\cline { 3 - 6 } & & Count & Percentage & Lower & Upper \\
\hline \multirow{3}{*}{ Type } & Congenital/developmental & 27 & 57.45 & 48.20 & 66.69 \\
\cline { 2 - 5 } & Traumatic cataract & 20 & 42.55 & 33.31 & 51.80 \\
\hline \multirow{4}{*}{ Presentation } & Defective vision & 23 & 48.94 & 39.59 & 58.28 \\
\cline { 2 - 6 } & Leukocoria & 14 & 29.79 & 21.24 & 38.34 \\
\cline { 2 - 6 } & Strabismus & 07 & 14.89 & 08.23 & 21.55 \\
\cline { 2 - 6 } & Screening & 03 & 06.38 & 01.81 & 10.95 \\
\hline
\end{tabular}

Table 3.2.1: Observed versus expected distribution of pediatric cataracts by sex in population of D.I.Khan District, Pakistan $(n=47)$

\begin{tabular}{|l|l|c|c|c|c|c|c|c|c|}
\hline Variable & Attributes & $\mathrm{O}$ & $\mathrm{E}$ & $\mathrm{O}-\mathrm{E}$ & $(\mathrm{O}-\mathrm{E})^{2}$ & $(\mathrm{O}-\mathrm{E})^{2} / \mathrm{E}$ & $\mathrm{X}^{2}$ value & d.f. & P-value \\
\hline \multirow{2}{*}{ Sex } & Boys & 29 & 36 & -7 & 49 & 1.36 & 5.81 & 1 & .0158 \\
\cline { 2 - 9 } & Girls & 18 & 11 & 7 & 49 & 4.45 & \multicolumn{2}{|c|}{$\mathrm{H}_{0} 1$ rejected } \\
\hline & Total & 47 & 47 & \multicolumn{6}{|c|}{ Chi-square goodness-of-fit with Yates correction at a 0.05} \\
\hline
\end{tabular}

$\mathrm{O}=$ Observed count, $\mathrm{E}=$ Expected count, d.f. $=$ degree of freedom, $\mathrm{X}^{2}=$ chi-square value

Table 3.2.2: Observed versus expected distribution of pediatric cataracts by age groups in population of D.I.Khan District, Pakistan $(n=47)$

\begin{tabular}{|l|l|c|c|c|c|c|c|c|c|}
\hline Variable & Attributes & $\mathrm{O}$ & $\mathrm{E}$ & $\mathrm{O}-\mathrm{E}$ & $(\mathrm{O}-\mathrm{E})^{2}$ & $(\mathrm{O}-\mathrm{E})^{2} / \mathrm{E}$ & $\mathrm{X}^{2}$ value & d.f. & $\mathrm{P}$ - value \\
\hline \multirow{2}{*}{ Age groups } & $<5$ years & 22 & 10 & 12 & 144 & 14.4 & 18.29 & 1 & .00002 \\
\cline { 2 - 9 } & $5-14$ years & 25 & 37 & -12 & 144 & 3.89 & \multicolumn{2}{|c|}{$\mathrm{H}_{0} 2$ rejected } \\
\hline & Total & 47 & 47 & \multicolumn{3}{|c|}{ Chi-square goodness-of-fit with Yates correction at a 0.05} \\
\hline
\end{tabular}

$\mathrm{O}=$ Observed count, $\mathrm{E}=$ Expected count, d.f. $=$ degree of freedom, $\chi^{2}=$ chi-square value

Boys $=93 * 47 / 120=36$ and girls $=27 * 47 / 120=11$

Putting observed and expected counts and running the test, we had $\mathrm{p}$-value less than alpha, so $\mathrm{H}_{0} 1$ was rejected, showing that the observations don't fits the statistical model of the population.

In simple words the 'observed' prevalence of cataract in our population is statistically significantly lower than we expected for boys \& higher than we expected for girls. (Table 3.2.1)

3.2.2 $\mathbf{H}_{0}$ 2: Our observed distribution for age group $<5$ years versus $5-14$ years was 22:25 $(n=47)$ against an expected distribution by Shah, et al. ${ }^{9}$ of $279: 1026$ $(n=1305)$. Chi-square goodness-of-fit test was used to testify the difference between the two distributions. For comparison we need same denominator, so we adjusted the expected counts for a sample of 47 . It came to be $36: 11$ for age group $<5$ years versus 5-14 years as under.

Age group $<5$ years $=279 * 47 / 1305=10$ and age group 5-14 years $=1026 * 47 / 1305=37$

Putting observed and expected counts and running the test, we had p-value less than alpha, so $\mathrm{H}_{0} 2$ was rejected, showing that the observations don't fits the statistical model of the population.

In simple words the 'observed' prevalence of cataract in our population is statistically significantly higher than we expected for age group $<5$ years \& lower than we expected for age group 5-14 years. (Table 3.2.2)

3.2.3 $\mathrm{H}_{0}$ 3: Our observed distribution for unilateral versus bilateral cataracts was 33:14 $(n=47)$ against an expected distribution by Naz, et al. of 29:91 $(n=120)$. Chi-square goodness-of-fit test was used to testify the difference between the two distributions. For comparison we need same denominator, so we adjusted the expected counts for a sample of 47 . It came to be $11: 36$ for unilateral versus bilateral as under.

Unilateral $=29 * 47 / 120=11$ and bilateral $=$ $91 * 47 / 120=36$

Putting observed and expected counts and running the test, we had $\mathrm{p}$-value less than alpha, so $\mathrm{H}_{0} 3$ was rejected, showing that the observations don't fits the statistical model of the population.

In simple words the 'observed' prevalence of cataract in our population is statistically significantly higher than we expected for unilateral \& lower than we expected for bilateral cataracts. (Table 3.2.3) 
Distribution of pediatric cataracts by sex, age groups, laterality, type and presentation in population...

Table 3.2.3: Observed versus expected distribution of pediatric cataracts by laterality in population of D.I.Khan District, Pakistan $(n=47)$

\begin{tabular}{|l|l|c|c|c|c|c|c|c|c|}
\hline Variable & Attributes & $\mathrm{O}$ & $\mathrm{E}$ & $\mathrm{O}-\mathrm{E}$ & $(\mathrm{O}-\mathrm{E})^{2}$ & $(\mathrm{O}-\mathrm{E})^{2} / \mathrm{E}$ & $\mathrm{X}^{2}$ value & d.f. & P- value \\
\hline \multirow{2}{*}{ Laterality } & Unilateral & 33 & 11 & 22 & 484 & 44.00 & 57.44 & 1 & $<.00001$ \\
\cline { 2 - 9 } & Bilateral & 14 & 36 & -22 & 484 & 13.44 & \multicolumn{2}{|c|}{$\mathrm{H}_{0} 3$ rejected } \\
\hline & Total & 47 & 47 & \multicolumn{2}{|c|}{ Chi-square goodness-of-fit with Yates correction at a 0.05} \\
\hline
\end{tabular}

$\mathrm{O}=$ Observed count, $\mathrm{E}=$ Expected count, d.f. $=$ degree of freedom, $\mathrm{X}^{2}=$ chi-square value

Table 3.2.4: Observed versus expected distribution of pediatric cataracts by type in population of D.I.Khan District, Pakistan $(n=47)$

\begin{tabular}{|c|c|c|c|c|c|c|c|c|c|}
\hline Variable & Attributes & $\mathrm{O}$ & $\mathrm{E}$ & O-E & $(\mathrm{O}-\mathrm{E})^{2}$ & $(\mathrm{O}-\mathrm{E})^{2} / \mathrm{E}$ & $\chi^{2}$ value & d.f. & P-value \\
\hline \multirow{3}{*}{ 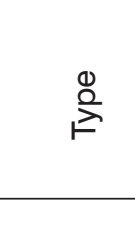 } & $\begin{array}{l}\text { Congenital/ } \\
\text { Developmental }\end{array}$ & 27 & 42 & -15 & 225 & 05.36 & 50.36 & 1 & $<.00001$ \\
\hline & $\begin{array}{l}\text { Traumatic } \\
\text { Cataract }\end{array}$ & 20 & 05 & 15 & 225 & 45.00 & \multicolumn{3}{|c|}{$\mathrm{H}_{0} 4$ rejected at a 0.05} \\
\hline & Total & 47 & 47 & \multicolumn{6}{|c|}{ Chi-square goodness-of-fit with Yates correction } \\
\hline
\end{tabular}

$\mathrm{O}=$ Observed count, $\mathrm{E}=$ Expected count, d.f. $=$ degree of freedom, $\chi^{2}=$ chi-square value

Table 3.2.5: Observed versus expected distribution of pediatric cataracts by presentation in population of D.I.Khan District, Pakistan $(n=47)$

\begin{tabular}{|c|c|c|c|c|c|c|c|c|}
\hline Variable & Attributes & $\mathrm{O}$ & $E$ & O-E & $(\mathrm{O}-\mathrm{E})^{2}$ & $(O-E)^{2} / E$ & $X^{2}$ value & P-value \\
\hline \multirow{4}{*}{ 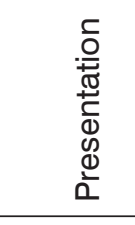 } & Defective vision & 23 & 19 & 4 & 16 & 0.84 & \multicolumn{2}{|c|}{ d.f. $=3, a=0.05$} \\
\hline & Leukocoria & 14 & 18 & -4 & 16 & 0.89 & \multirow{2}{*}{6.17} & \multirow{2}{*}{.1033} \\
\hline & Strabismus & 07 & 09 & -2 & 04 & 0.44 & & \\
\hline & Screening & 03 & 01 & 2 & 04 & 4.00 & \multicolumn{2}{|c|}{$\mathrm{H}_{05}$ accepted } \\
\hline & Total & 47 & 47 & \multicolumn{5}{|c|}{ Chi-square goodness-of-fit with Yates correction } \\
\hline
\end{tabular}

$O=$ Observed count, $E=$ Expected count, d.f. $=$ degree of freedom, $\chi^{2}=$ chi-square value

3.2.4 $\mathrm{H}_{0}$ 4: Our observed distribution for congenital/ developmental (non-traumatic) cataract versus traumatic cataract was 27:20 $(n=47)$ against an expected distribution by Johar, et al. ${ }^{12}$ of 152:20 $(n=172)$. Chi-square goodness-of-fit test was used to testify the difference between the two distributions. For comparison we need same denominator, so we adjusted the expected counts for a sample of 47 . It came to be $42: 5$ for congenital/ developmental cataract versus traumatic cataract as under.

Congenital/ developmental $=152 * 47 / 172=42$ and traumatic $=20 * 47 / 172=5$

Putting observed and expected counts and running the test, we had $p$-value less than alpha, so $\mathrm{H}_{0} 1$ was rejected, showing that the observations don't fits the statistical model of the population.

In simple words the 'observed' prevalence of cataract in our population is statistically significantly lower than we expected for congenital/ developmental cataract \& higher than we expected for traumatic cataract. (Table 3.2.4)

3.2.5 $\mathbf{H}_{0}$ 5: Our observed distribution for defective vision, leukocoria, strabismus and screening was
23:14:7:03 $(n=47)$ against an expected distribution of 214:202:95:09 $(n=520)$ by Zhu, et al. ${ }^{17}$ Chi-square goodness-of-fit test was used to testify the difference between the two distributions. For comparison we need same denominator, so we adjusted the expected counts for a sample of 47 . It came to be 19:18:09:01 for defective vision, leukocoria, strabismus and screening as under.

Defective vision $=214 * 47 / 520=19$, leukocoria $=$ $202 * 47 / 520=18$, strabismus $=95 * 47 / 520=09$ and screening $=9 * 47 / 520=01$.

Putting observed and expected counts and running the test, we had p-value more than alpha, so $\mathrm{H}_{0} 5$ was accepted, showing that the observations fit the statistical model of the population.

In simple words the 'observed' presentation of cataract through four given attributes in our population is statistically similar to what we expected from literature. (Table 3.2.5)

\section{DISCUSSION}

4.1 Distribution of pediatric cataracts by sex. (Objective 1 \& 6, $\mathrm{H}_{0} 1$ ) 
The prevalence of pediatric cataracts in our sample and population was higher for boys $61.7 \%(80 \%$ $\mathrm{Cl} 52.62-70.79 \%)$ than girls $38.3 \%(80 \% \mathrm{Cl} 29.21$ $47.38 \%)$.

Similar findings of higher prevalence rate for boys $77.5 \%(93 / 120)$ than girls $22.5 \%$ (27/120) was reported by Naz, et al. ${ }^{5}$ from Lahore, Pakistan and $60.38 \%$ (314/520) boys and $39.62 \%$ (206/520) girls by Zhu, et al. ${ }^{7}$ for the period from April 2009 to April 2014 from Shanghai, China.

Higher prevalence rate for girls $53 \%(31 / 59)$ than boys $47 \%$ (28/59) was reported by Fakhoury, et al. ${ }^{8}$ in epidemiological study over 10 years, published in 2015 from France.

Equal prevalence for boys and girls was reported by Rahi \& Dezateux ${ }^{2}$; boys $52.42 \%$ (130/248) and girls $47.58 \%(118 / 248)$ in UK in 1995-96 and by Haargaard, et $\mathrm{al}^{6}$ in nation-wide Danish study in 2004 with boys $51.50 \%(529 / 1027)$ and girls $48.50 \%$ (498/1027).

With almost equal global and Pakistan population of boys and girls, equal prevalence of pediatric cataract has logical explanation. Unequal prevalence needs further investigation.

4.2 Distribution of pediatric cataracts by age groups. (Objective $2 \& 7, \mathrm{H}_{0} 2$ )

The prevalence of pediatric cataracts in our sample and population was higher for age group 5-14 years $53.19 \%(80 \% \mathrm{Cl} 43.86-62.52 \%)$ than for age group $<5$ years $46.81 \%(80 \% \mathrm{Cl} 37.48-56.14)$.

Similar to our findings are from Shah, et al. ${ }^{9}$ showing higher prevalence for age group 6-18 years as $78.62 \%(1026 / 1305)$ than age group $0-5$ years as $21.38 \%(279 / 1305)$ in a study for a period from January 1999 to April 2012 in Dahod, Gujarat, India.

Shrestha \& Shrestha ${ }^{13}$ reported $31.8 \%$ (42/132) cases in age group 0-3 years, 22.7\% (30/132) in age group $>3-7$ years and $45.5 \%(60 / 132)$ cases in age group $>7-14$ years from Kathmandu, Nepal for the period from November, 2007 to June, 2009.

Higher prevalence for older children (5-10 years) than younger children ( $<5$ years) in our study can be explained by the fact that 20 out of 47 cases were traumatic and older children are relatively more exposed to trauma.

4.3 Distribution of pediatric cataracts by laterality. (Objective 3 \& 8, $\mathrm{H}_{0} 3$ )

The prevalence of unilateral cataracts in our sample and population was higher $70.21 \%(80 \% \mathrm{Cl} 61.66-$ $78.76 \%)$ than bilateral cataracts $29.79 \%(80 \% \mathrm{Cl}$ 21.24-38.34\%).

The following authors have also reported higher prevalence for unilateral than bilateral pediatric cataracts. Tartarella, et al. ${ }^{11}$ have reported unilateral in $52.66 \%(109 / 207)$ and bilateral in $47.34 \%$ (98/207) cases for the period from February 2001 to January
2011 from São Paulo, Brazil. Tomkins, et al. ${ }^{12}$ found unilateral cataract in $75.34 \%$ (55/73) and bilateral in $24.66 \%$ (18/73) cases in Hawassa, Ethiopia for the period from July 31, 2007, through August 1, 2008. Shrestha \& Shrestha ${ }^{13}$ reported unilateral cataract in $67.4 \%(89 / 132)$ and bilateral in $32.6 \%(43 / 132)$ cases in Kathmandu, Nepal for the period from November, 2007 to June, 2009.

On contrary, the following authors have reported higher prevalence for bilateral than unilateral pediatric cataracts. Naz, et al. ${ }^{5}$ showed bilateral cataracts in $75.83 \%(91 / 120)$ and unilateral in $24.17 \%(29 / 120)$ cases. Zhu, et al. ${ }^{7}$ showed bilateral in $56.35 \%$ $(293 / 520)$ and unilateral in $43.65 \%(227 / 520)$ cases. Fakhoury, et al. ${ }^{8}$ showed bilateral cataracts in $71 \%$ $(42 / 59)$ and unilateral in 29\% (17/59) cases and Qi, et al. ${ }^{10}$ for the period from January 2004 to January 2012 from Shenyang, Liaoning Province, China, showed $78 \%$ (25/32) bilateral cases and 22\% (7/32) unilateral cases.

While almost equal prevalence is reported for unilateral $48.8 \%(160 / 328)$ and bilateral cataracts $51.2 \%$ (168/328) from Guatemala City, Republic of Guatemala for the period from 2000 to 2007 by Zimmermann-Paiz \& Quiroga-Reyes. ${ }^{14}$

Higher prevalence of unilateral cataracts in our study can be explained by the fact that 20 out of 47 cases were traumatic in origin and traumatic cases are almost always unilateral.

4.4 Distribution of pediatric cataracts by type. (Objective 4 \& 9, $\mathrm{H}_{0} 4$ )

Congenital/ developmental cataracts were more common as $57.45 \%(80 \% \mathrm{Cl} 48.20-66.69)$ than traumatic cataracts as $42.55 \%(80 \% \mathrm{Cl} 33.31-51.80)$ in our sample and population.

Similar to our findings are from the following three studies. In a study for the period from 1985-1990, by Hochstrasser, et al. ${ }^{15}$ from Zürich, Switzerland, congenital/ developmental cataracts were found in $60 \%(45 / 75)$ cases while traumatic cataracts were found in $40 \%(30 / 75)$ cases. Johar, et al. ${ }^{16}$ found $88.4 \%(152 / 172)$ non-traumatic cataracts and $11.6 \%$ (20/172) traumatic cataracts in a hospital-based etiological study of pediatric cataracts in Western India. Mohan \& Kaur ${ }^{17}$ found $72.12 \%$ (119/165) non-traumatic cataracts and $27.88 \%(46 / 165)$ traumatic cataracts from April 2011 to March 2014 in a hospital-based study of pediatric cataracts from Abu Road city, Sirohi district of Rajasthan state in western India.

4.5 Distribution of pediatric cataracts by presentation. (Objective 5 \& 10, $\mathrm{H}_{0} 5$ )

The presentation of cataract in our sample and population was by defective vision in $48.94 \%$ ( $80 \%$ $\mathrm{Cl} 39.59-58.28)$, leukocoria in $29.79 \%(80 \% \mathrm{Cl} 21.24-$ $38.34)$, strabismus in $14.89 \%(80 \% \mathrm{Cl} 8.23-21.55)$ and through screening in $6.38 \%(80 \% \mathrm{Cl} 1.81-10.95)$. 
Zhu, et al. ${ }^{7}$ form China found the mode of presentation as defective vision in $41.3 \%(214 / 520)$, leukocoria in $38.8 \%(202 / 520)$, strabismus in $18.3 \%(95 / 520)$ and through screening in $1.73 \%(9 / 520)$ cases. Fakhoury, et al. ${ }^{8}$ from France found the presentation as systematic screening in $41 \%(24 / 59)$, leukocoria in $24 \%(14 / 59)$ and strabismus in $19 \%(11 / 59)$ cases.

\subsection{Strengths of the study:}

4.6.1 Research is a problem solving process for a specified population. We have defined our population by count and selection criteria, drawn a sample, observed and described the sample for variables of interest (descriptive statistics), inferred the sample results to describe the population (estimation of parameter- inferential statistics) and then compared the observed parameters of our population against certain expected parameters to see if our population behaves like other populations or is it different (hypothesis testing- inferential statistics)? ?3-24 $^{23}$

All the studies mentioned here in introduction and discussion start from sample and end on the sample; no proper mention of a specified population, no proper sampling, no estimation of parameters or hypothesis testing to address their populations.

We were supposed to compare our population to other local, national, regional and global populations through the results of hypotheses testing to see similarities and dissimilarities between them. As none of the cited studies have put and tested their hypotheses, so we had no option except to compare our sample results to the sample results of other relevant studies, assuming their sample statistics as their point estimates.

4.6.2 Our study has a logical flow as adopted from the "Marwat's Logical Trajectory of Research Process". ${ }^{23-24}$ Starting from the research problems through knowledge gaps, research questions, research objectives and research hypotheses, data was collected for the variables of interest, analyzed and interpreted, so that hypotheses were tested, objectives were met, research questions were answered, knowledge gaps were filled and finally the research problems were solved.

\subsection{Weakness of the study}

Our sample size is not large enough. Still it is one year data of an uncommon disease of pediatric cataracts from a population of a district. We had to decrease our confidence level to $80 \%$ to have meaningful confidence intervals for proportions to describe our population parameters from sample statistics.

\section{CONCLUSIONS}

The prevalence of pediatric cataract was higher for boys than girls and higher for older children (5-14 years) than younger ( $<5$ years) children. Unilateral were more common than bilateral cataracts and the congenital/ developmental cataracts were more com- mon than traumatic cataracts. Defective vision was the most common presentation of pediatric cataracts.

Acknowledgement: Our co-author Dr. Muhammad Marwat is acknowledged for re-shaping the manuscript in an innovative format in the light of his "Marwat's Logical Trajectory for Research Process" and also for the advanced statistical analysis in a valid, reliable, verifiable and replicable way.

\section{REFERENCES}

1. Shamanna BR, Muralikrishnan R. Childhood cataract: magnitude, management, economics and impact. Community Eye Health 2004; 17:17-8.

2. Rahi JS, Dezateux C. British Congenital Cataract Interest Group. Measuring and interpreting the incidence of congenital ocular anomalies: lessons from a national study of congenital cataract in the UK. Invest Ophthalmol Vis Sci 2001 Jun; 42(7):1444-8.

3. Sheeladevi S, Lawrenson JG, Fielder AR, Suttle CM. Global prevalence of childhood cataract: a systematic review. Eye 2016; 30 (9): 1190-6. https://doi.org/10.1038/eye.2016.156

4. Jadoon Z, Shah SP, Bourne R, Dineen B, Khan MA, Gilbert CE, et al. Cataract prevalence, cataract surgical coverage and barriers to uptake of cataract surgical services in Pakistan: the Pakistan National Blindness And Visual Impairment Survey. Br J Ophthalmol 2007; 91:1269-73. https://doi. org/10.1136/bjo.2006.106914

5. Naz S, Sharif S, Badar H, Rashid F, Kaleem A, Iqtedar M. Incidence of environmental and genetic factors causing congenital cataract in Children of Lahore. J Pak Med Assoc 2016 Jul; 66 (7):819-22.

6. Haargaard B, Wohlfahrt J, Fledelius HC, Rosenberg T, Melbye M. A nationwide Danish study of 1027 cases of congenital/ infantile cataracts: etiological and clinical classifications. Ophthalmology 2004 Dec 01; 111 (12): 2292-8. https:// doi.org/10.1016/j.ophtha.2004.06.024

7. Zhu X, Du Y, He W, Sun T, Zhang Y, Chang R, et al. Clinical features of congenital and developmental cataract in East China: A five-year retrospective review. Sci Rep 2017 Jun 26; 7(1):4254. https:// doi.org/10.1038/s41598-017-04332-1

8. Fakhoury O, Aziz A, Matonti F, Benso C, Belahda K, Denis D. Epidemiologic and etiological characteristics of congenital cataract: study of 59 cases over 10 years. J Fr Ophthalmol 2015 Apr; 38 (4):295-300. https://doi.org/10.1016/j. jfo.2014.10.012

9. Shah MA, Shah SM, Shikhangi KA, Upadhyay PR, Bardoloi GB. Factors affecting visual outcome following surgical treatment of cataracts in children. Open J Ophthalmol 2012; 2:131-9. https:// doi.org/10.4236/ojoph.2012.24029

10. Qi JY, Xiao W, Wang MY, Zhao DX, Pu W. Longterm outcomes after cataract surgery in infants with congenital cataract. Zhonghua Yan $\mathrm{Ke} \mathrm{Za}$ Zhi 2017 Apr 11; 53(4):266-73. doi:10.3760/cma .j.issn.0412-4081.2017.04.008 
11. Tartarella MB, Britez-Colombi GF, Milhomem S, Lopes Márcia CE, Fortes Filho J B. Pediatric cataracts: clinical aspects, frequency of strabismus and chronological, etiological, and morphological features. Arq Bras Oftalmol 2014; 77 (3):143-7. https://doi.org/10.5935/0004-2749.20140037

12. Tomkins O, Ben-Zion I, Moore DB, Helveston EE. Outcomes of pediatric cataract surgery at a tertiary care center in rural Southern Ethiopia. Arch Ophthalmol 2011; 129 (10): 1293-7. https://doi. org/10.1001/archophthalmol.2011.268

13. Shrestha U, Shrestha M. Clinical profile of paediatric cataract and surgery in a tertiary eye care centre, Nepal. J Nepal Paediatr Soc 2012 Feb 18; 32(1): 14-8. https://doi.org/10.3126/jnps. v32i1.5378

14. Zimmermann-Paiz MA, Quiroga-Reyes CR [article in Spanish]. Pediatric cataract in a developing country: retrospective review of 328 cases. Arq Bras Oftalmol 2011 May-Jun; 74 (3): 163-5. https:// doi.org/10.1590/S0004-27492011000300003

15. Hochstrasser P, Gloor B. Surgical results of uni- and bilateral congenital and traumatic cataract in infancy to adolescence. Klin Monbl Augenheilkd 1994 May; 204(5):274-8. https://doi. org/10.1055/s-2008-1035534

16. Johar SR, Savalia NK, Vasavada AR, Gupta PD. Epidemiology based etiological study of pediatric cataracts in western India. Indian J Med Sci 2004 Mar; 58(3): 115-21.

17. Mohan A, Kaur N. Pattern of presentation of pediatric cataract in tribes of hills of Western India: A hospital-based retrospective study at Global
Hospital Institute of Ophthalmology, Mount Abu. J Clin Sci 2017; 14:178-81. https://doi.org/10.4103/ jcls.jcls_59_17

18. Raosoft ${ }^{\circledR}$ sample size calculator [internet]. Seattle, WA, USA: Raosoft Inc.; 2004. [accessed 2017 Jan 13]. Available at: http://www. Raosoft. com/ samplesize.html

19. Statistics Kingdom. Proportion confidence interval calculator [internet]. Statistics Kingdom; Melbourne, Australia 2007. [accessed 2018 Oct 12]. Available at: http://www.statskingdom. com/41_proportion_confidence_interval.html

20. Zar JH. Biostatistical Analysis. 5th ed. New York: Prentice-Hall, Inc.

21. Daniel WW. Biostatistics: A Foundation for Analysis in the Health Sciences. 7th ed. Singapore: John Wily; 2005.

22. Jeremy Strangroom. Chi-Square Test Calculator. Social Sciences Statistics. (accessed 2018 Nov 13). Available at: https: socscistatistics.com/tests/ chisquare2/Default2/aspx

23. Shah S, Basharat A, Shah M, Marwat M, Billah M, Ali SM. Frequency, distribution and presentation of hypocalcemia in B-thalassemia major. Gomal J Med Sci 2018 Jan-Mar; 16(1):2-8. https://doi. org/10.46903/gjms/16.01.1446

24. Shah HU, Gul H, Khan R, Marwat M. Urethrocutaneous fistula following Snodgrass versus two stage Aivar Bracka repair of distal penile hypospadias in male children: a randomized control trial. Gomal J Med Sci 2018 Apr-Jun; 16 (2): 54-8. https://doi.org/10.46903/gjms/16.02.1284

CONFLICT OF INTEREST

Authors declare no conflict of interest. GRANT SUPPORT AND FINANCIAL DISCLOSURE None declared.

\section{AUTHORS' CONTRIBUTION}

The following authors have made substantial contributions to the manuscript as under:

Conception or Design:

Acquisition, Analysis or Interpretation of Data:

Manuscript Writing \& Approval:

$$
\begin{aligned}
& \text { MKK, IA, MM } \\
& \text { MKK, IA, MAK, MS, MI, MM } \\
& \text { MKK, IA, MAK, MS, MI, MM }
\end{aligned}
$$

All the authors agree to be accountable for all aspects of the work in ensuring that questions related to the accuracy or integrity of any part of the work are appropriately investigated and resolved. 